\title{
BMJ Open Prevalence of occupational exposure and its influence on job satisfaction among Chinese healthcare workers: a large- sample, cross-sectional study
}

\author{
Yu Shi (D) , ${ }^{1}$ Haifeng Xue, ${ }^{2}$ Yuanshuo Ma, ${ }^{1}$ Licheng Wang, ${ }^{3}$ Tian Gao, ${ }^{4}$ Lei Shi, ${ }^{1}$ \\ Yang Wang, ${ }^{5}$ Mei Cui, ${ }^{6}$ Chao Wang, ${ }^{7}$ Xi Yang, ${ }^{1}$ Ming Liu, ${ }^{1}$ Lihua Fan, ${ }^{1}$ Guanyun Yan $^{8}$
}

To cite: Shi Y, Xue H, Ma Y, et al. Prevalence of occupational exposure and its influence on job satisfaction among Chinese healthcare workers: a large-sample, crosssectional study. BMJ Open 2020;10:e031953. doi:10.1136/ bmjopen-2019-031953

- Prepublication history for this paper is available online. To view these files, please visit the journal online (http://dx.doi org/10.1136/bmjopen-2019031953).

Received 28 May 2019 Revised 26 November 2019 Accepted 05 February 2020
Check for updates

(C) Author(s) (or their employer(s)) 2020. Re-use permitted under CC BY-NC. No commercial re-use. See rights and permissions. Published by BMJ.

For numbered affiliations see end of article.

Correspondence to

Professor Lihua Fan;

lihuafan@126.com,

Professor Haifeng Xue; xuehaifeng2011049@163. com and

Mr Guanyun Yan;

hydygy@126.com

\section{ABSTRACT}

Objectives This study had three objectives: (1) describe the prevalence of occupational exposure among Chinese medical personnel in detail, (2) verify the partial mediating role of work environment satisfaction in the relationship between occupational exposure and job satisfaction, and (3) examine if stress symptoms moderate the relationship between occupational exposure and job satisfaction.

Design A large cross-sectional online survey was conducted in July 2018 in China.

Setting A survey was conducted in 54 cities across 14 provinces of China.

Participants A total of 12784 questionnaires were distributed, and 9924 healthcare workers (HCWs) completed valid questionnaires. The response rate was $77.63 \%$.

Outcome measures A confidential questionnaire was distributed to HCWs. The relationships among and the mechanisms of the variables were explored using descriptive statistical analyses, Pearson's correlation coefficient and multiple linear regression analysis.

Results The most common occupational exposures among HCWs in the past 12 months were psychosocial and organisational hazards (85.93\%). Overall, physicians $(93.7 \%)$ and nurses (89.2\%) were the main victims of occupational exposure. Occupational exposure correlated negatively with work environment satisfaction and job satisfaction, and positively with stress symptoms. Moreover, work environment satisfaction fully mediated the relationship between occupational exposure and job satisfaction, and stress symptoms moderated the relationship between occupational exposure and job satisfaction.

Conclusion The incidence of occupational exposure among HCWs is generally high. The high frequency of psychosocial and organisational hazards among physicians and nurses should be taken seriously and dealt with in a timely manner by hospital managers. The negative impact of occupational exposure on job satisfaction must be buffered by measures to reduce stress symptoms and enhance working environment satisfaction, ultimately improving the overall quality of life of HCWs and promoting comprehensive development of the medical team.
Strengths and limitations of this study

- This large-sample study focused on the topic of occupational exposure among healthcare workers (HCWs) in China.

- A large-sample survey was conducted to investigate the incidence of five types of occupational exposure among HCWs.

- The publication of this article will further promote China's hospital management policy on occupational safety of HCWs.

- Self-reports of HCWs through an online survey may have resulted in response bias.

- To potentially increase response rates, several single-item tools through short survey materials were used in this study for collecting data, but it also potentially reduced the validity and reliability of the measurement.

\section{INTRODUCTION}

Hospitals and healthcare workers (HCWs) have previously focused on using their maximum potential to provide quality services to patients, while largely neglecting their occupational safety. ${ }^{1}$ The medical services industry has poor health and safety record, and has paid little attention to training its members in minimising risks. ${ }^{2}$ Previous surveys conducted in American teaching hospitals have reported exposures to patients' blood and body fluids of between $19 \%$ and $71 \%$ among HCWs, residents and medical students. ${ }^{3}$ Additionally, in 2007, Safe Work Australia reported that paramedics have the sixth highest rate of occupational injuries. ${ }^{4}$ Ambulance officers and paramedics had an upward trend in risk of musculoskeletal (MSK) claim rates for all injuries and the highest rates for MSK and mental injury based on an analysis of workers' compensation claims from 2003 to $2012 .^{5}$ The rate of non-fatal injuries among US paramedics was 


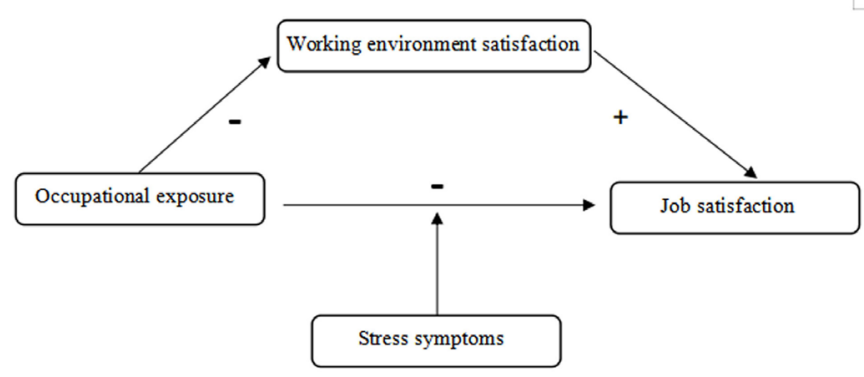

Figure 1 Conceptual model.

34.6 per 100 full-time workers per year, which was more than five times higher than the national average for all workers. ${ }^{6}$ Therefore, HCWs' occupational exposure should be an important concern among managers.

Occupational exposure can be defined as the presence of a substance or risk factor in the work environment external to the worker. The Encyclopedia of Public Health indicates five types of occupational exposure: accident, physical, chemical, biological, psychosocial and organisational factors. ${ }^{7}$ The International Hazard Datasheets on Occupations further clarifies the concept and types of occupational exposure among nurses. ${ }^{8}$ Occupational exposures include physical hazards, chemical hazards, ${ }^{9} 10$ biological hazards, ${ }^{11}{ }^{12}$ accident-related hazards, ${ }^{13}{ }^{14}$ and psychosocial and organisational factors. ${ }^{15-17}$ HCWs can face the abovementioned five types in their daily work. They can easily be harmed by dangers in their work environment if they do not pay attention to personal protection during diagnosis, treatment, nursing and surgery. ${ }^{18} 19$ Therefore, there should be policies and processes to protect HCWs; their protection involves both individual and organisational actions.

Previous research has examined the occupational exposure experienced by nurses and physicians in China, including aspects related to AIDS, tuberculosis and other infectious diseases. ${ }^{20} 21$ Occupational exposure affects HCWs not only physically but also psychologically. Deterioration of the physician-patient relationship has emerged as a highly visible risk to China's ambitious healthcare reform. ${ }^{1722}$ In China, currently, the physicianpatient relationship has reached an unprecedented level of tension. ${ }^{2223}$ Physician-patient conflicts occur in various forms, including violent attacks on individuals and disruption of clinical work. In China, conflicts between HCWs and patients are more prominent than those between colleagues. Overwork is also a significant challenge facing HCWs in China, especially in urban tertiary hospitals. ${ }^{24}{ }^{25}$ In short, overwork, exhaustion and workplace violence are specific challenges faced by HCWs in China.

Furthermore, numerous studies have indicated that job satisfaction among staff is mainly affected by work environment, work intensity, salary level, interpersonal relationships and development prospects. ${ }^{26}{ }^{27}$ Medical work environment and work intensity affect the risk of occupational exposure. ${ }^{28}{ }^{29}$ Additionally, the fragility of the interpersonal relationships between HCWs and patients has been emphasised. ${ }^{30} \mathrm{HCW}$ are directly exposed to the risk of medical responsibility in the crisis of trust between physicians and patients, which increases psychological pressure. $^{31}$

Moreover, long-term accumulation of stress may reduce HCWs' job satisfaction. Previous studies have indicated that improving safety and mobilising positive emotions can improve job satisfaction level. ${ }^{32}$ Additionally, stress has a wide impact on many individual factors, including physical and mental health, emotional state, life and job satisfaction, and quality of life. ${ }^{33} \mathrm{~A}$ previous study pointed out that the working environment of HCWs mainly includes objective environment and interpersonal environment. ${ }^{3435}$ This study focuses on HCWs' satisfaction with their own working environment, which is very valuable for research on occupational exposure in the medical working environment. In sum, this study proposed the following hypotheses:

- Hypothesis 1: Work environment satisfaction plays a mediating role in the relationship between occupational exposure and job satisfaction among HCWs.

- Hypothesis 2: HCWs' stress symptoms moderate the relationship between occupational exposure and job satisfaction.

The hypothetical conceptual model is shown in figure 1. Hypotheses 1 and 2 were tested in one model. We conducted a large-scale, cross-sectional occupational health survey of HCWs in China to investigate the current level of their occupational exposure and the mechanisms influencing job satisfaction.

\section{MATERIALS AND METHODS Sample/Participants}

This cross-sectional study was conducted using an online questionnaire with HCWs in 14 provinces (including Chongqing, Guizhou, Heilongjiang, Beijing and Qinghai) in China. The questionnaires were forwarded by the HCW working group and were answered using a mobile device or computer. HCWs participated in the survey using the access link or the Quick Response $(\mathrm{QR})$ code of the online questionnaire through a platform called 'Lediaocha'. Once the questionnaire was completed, the data management platform received the corresponding records and recorded participants' time spent in answering. A response time of less than 5 min was considered invalid because a presurvey test to determine a valid questionnaire completion time reported a time of more than $5 \mathrm{~min}$; additionally, a quality control topic was set at the end of the questionnaire. Participants were asked to make a subjective assessment of their response process after completing the questionnaire, choosing the following responses: 'because of some reasons, I failed to fill in this questionnaire seriously, and recommend to exclude this questionnaire' and 'because of some other reasons, I was disturbed and can only ensure that a small part of the questionnaire was carefully completed'. These responses were excluded from the analysis. The 
inclusion criteria for the study included being an HCW and a regular employee of the hospital, having more than 1 year of experience as an HCW, and providing informed consent for voluntary participation. The data management platform showed that a total of 12784 questionnaires were distributed, and 9924 participants completed valid questionnaires. The response rate was $77.63 \%$.

\section{Data collection}

The confidential online questionnaire was completed by HCWs throughout the country from 10 July to 10 October 2018. This large-scale, cross-sectional survey was successfully completed with the assistance of the members of the Hospital Occupational Health Group of Quality, Health, Safety, and Environmental Protection of the Management Committee of China Research Hospital Association. The questionnaire is compiled on the internet. Participants can easily participate in the survey by generating the access link and $\mathrm{QR}$ code of the internet questionnaire through a platform called 'happy survey'. We usually used a WeChat group to forward the questionnaires. A web link to our questionnaire survey (https://www.lediaocha. com/survey) was sent via mobile phone to participants outside of working hours. We monitored the collected questionnaires in real time and effectively managed the data using the data management platform.

\section{Questionnaire}

\section{Occupational exposure}

The measurement of occupational exposure was derived from the classification of occupational hazards in nursing according to the International Occupational Hazards Database of the International Labour Organization Occupational Safety and Health Information Centre. ${ }^{8}$ Occupational exposure among HCWs in the previous 12 months was assessed using the 28-item, self-report, fivedimensional model of occupational exposure revised by Li et $a l,{ }^{36}$ with items rated on a 5-point Likert-type scale ranging from 1 to 5 (1=seldom, 2=fewer, $3=$ =sometimes, $4=$ often, $5=$ frequently). The total occupational exposure score is computed to quantify the respondent's overall level of occupational exposure. A total score of 28 represents those unexposed to occupational hazards and a score of $\geq 29$ represents those who are exposed. This inventory of occupational exposure was suitable for a medical context. ${ }^{37}$ It contains five dimensions (accidental hazards, physical hazards, chemical hazards, biological hazards, and psychosocial and organisational factors). Being exposed to occupational hazards was defined as responding positively to any of the items. The Cronbach's alpha of the five dimensions are $0.819,0.782,0.797,0.820$ and 0.872 , respectively.

\section{Work environment satisfaction}

Work environment satisfaction was evaluated with a single item: 'What is the level of your satisfaction with the environment where you work? (mainly refers to the safety, comfort, and harmony of the objective hospital environment in which you work, excluding salary and promotion factors)'. This item was scored on a 5-point Likert-type scale ranging from 1 to 5 (1=very satisfied, $2=$ satisfied, $3=$ neutral, $4=$ dissatisfied, $5=$ very dissatisfied). The item was reverse-scored to facilitate data analysis. Thus, higher scores indicated higher work environment satisfaction.

\section{Stress symptoms}

A single item was used to measure stress symptoms among HCWs, as suggested by Elo $^{38}$ : 'A person falls into a state of nervous tension, uneasiness, nervousness, anxiety, or sleeplessness at night because of certain psychological reasons. Have you ever felt this way in recent years? What is the degree of this feeling?' Participants were requested to rate their symptoms on a 5-point scale from 'never' to 'very serious', with higher scores indicating higher stress.

\section{Job satisfaction}

Job satisfaction was evaluated with a single item: 'Overall, how satisfied are you with your current job?' This item was rated on a 5-point Likert-type scale ranging from 1 to 5 ( $1=$ very satisfied, $2=$ satisfied, $3=$ neutral, $4=$ dissatisfied, $5=$ very dissatisfied). In a previous research, this item had adequate reliability and validity. ${ }^{39}$

\section{Data analysis}

\section{Preliminary analyses}

A descriptive statistical analysis was used to investigate the demographic characteristics of HCWs. Frequencies, means and SDs were used to describe the characteristics of the sample. The correlations between the study variables (occupational exposure, work environment satisfaction, stress symptoms and job satisfaction) were examined using Pearson's correlation coefficient. All analyses were conducted using SPSS V.19.0. Statistical significance was defined as a two-tailed $\mathrm{p}$ value of $<0.05$.

\section{Mediation and moderation analyses}

First, mediation analysis was used to identify and explicate the relationship between the dependent variable "job satisfaction' and the independent variable 'occupational exposure', which may be affected by a third variable 'work environment satisfaction'. A hierarchical regression analysis was conducted to test the mediation effects. The mediation mechanism was calculated with the SPSS macro PROCESS by Hayes. ${ }^{40}$ The mediation analyses were based on bootstrapping (5000 bootstrap samples) using 95\% CIs. The macro PROCESS was used for calculating and testing the direct effect, indirect effect and moderating effect. The mediation mechanism is significant when the $95 \%$ CI does not include 0 . The gender, health worker discipline types, department, service years, education and medical institution level were included as control variables.

\section{Patient and public involvement}

Neither the patients nor the public were involved in the development of the methodology for the current study. 


\begin{tabular}{|c|c|c|c|}
\hline Characteristics & Classes & $\mathbf{n}$ & $\%$ \\
\hline \multirow[t]{4}{*}{$\begin{array}{l}\text { Medical } \\
\text { institution level }\end{array}$} & $\begin{array}{l}\text { Primary healthcare } \\
\text { institutions }\end{array}$ & 21 & 0.2 \\
\hline & Secondary hospital & 853 & 8.6 \\
\hline & Tertiary hospitals & 8715 & 87.8 \\
\hline & Unsure & 335 & 3.4 \\
\hline \multirow[t]{3}{*}{ Gender } & Male & 3560 & 35.9 \\
\hline & Female & 6300 & 63.5 \\
\hline & Unsure & 64 & 0.6 \\
\hline \multirow[t]{5}{*}{ Discipline types } & Nurse & 5872 & 59.2 \\
\hline & Medical technician & 1149 & 11.6 \\
\hline & Pharmacist & 212 & 2.1 \\
\hline & Physician & 2553 & 25.7 \\
\hline & Unsure & 138 & 1.4 \\
\hline \multirow[t]{5}{*}{ Service years } & $1-5$ & 3652 & 36.8 \\
\hline & $6-10$ & 2767 & 27.9 \\
\hline & $11-15$ & 1377 & 13.9 \\
\hline & $16-20$ & 717 & 7.2 \\
\hline & $>20$ & 1411 & 14.2 \\
\hline \multirow{4}{*}{$\begin{array}{l}\text { Professional } \\
\text { ranks and titles }\end{array}$} & Junior & 5411 & 54.5 \\
\hline & Intermediate & 2709 & 27.3 \\
\hline & Senior & 1259 & 12.7 \\
\hline & Non-ranked & 545 & 5.5 \\
\hline \multirow[t]{6}{*}{$\begin{array}{l}\text { Degree of } \\
\text { education }\end{array}$} & $\begin{array}{l}\text { Below secondary } \\
\text { specialised school }\end{array}$ & 11 & 0.1 \\
\hline & $\begin{array}{l}\text { Secondary specialised } \\
\text { school }\end{array}$ & 179 & 1.8 \\
\hline & Junior college & 2350 & 23.2 \\
\hline & Undergraduate & 6023 & 60.7 \\
\hline & Master's candidate & 141 & 1.4 \\
\hline & Doctoral candidate & 1265 & 12.7 \\
\hline \multirow[t]{5}{*}{ Marital status } & Unmarried & 2767 & 27.9 \\
\hline & Married & 6947 & 70 \\
\hline & Widowed & 23 & 0.2 \\
\hline & Divorced & 8 & 0.1 \\
\hline & Unsure & 179 & 1.8 \\
\hline
\end{tabular}

However, academic discussion with previous scholars and the status of occupational exposure of HCWs have jointly promoted the design and implementation of this study.

\section{RESULTS}

The demographic characteristics of the respondents are shown in table 1 . Most participants were from tertiary hospitals (87.8\%), and more than half were female $(63.5 \%)$. Nurses $(59.2 \%)$, physicians $(25.7 \%)$ and medical technicians $(11.6 \%)$ were the main occupational groups of respondents in this sample and their service years were mostly 1-10 years $(64.7 \%)$. Approximately half of the
Table 2 Occupational exposure scores of healthcare workers within the last 12 months

\begin{tabular}{llll}
\hline $\begin{array}{l}\text { Occupational } \\
\text { exposure types }\end{array}$ & $\begin{array}{l}\text { Exposure } \\
\text { status }\end{array}$ & $\mathbf{n}$ & $\begin{array}{l}\text { Exposure } \\
\text { rate (\%) }\end{array}$ \\
\hline $\begin{array}{l}\text { Psychosocial and } \\
\text { organisational factors }\end{array}$ & $\begin{array}{l}\text { Unexposed } \\
\text { Exposed }\end{array}$ & 1396 & 85.93 \\
\hline Accidental hazards & Unexposed & 2900 & 70.78 \\
& $\begin{array}{l}\text { Exposed } \\
\text { Unexposed }\end{array}$ & 7024 & \\
Biological hazards & $\begin{array}{l}\text { Unexp } \\
\text { Exposed }\end{array}$ & 6347 & 63.96 \\
Physical hazards & $\begin{array}{l}\text { Unexposed } \\
\text { Exposed }\end{array}$ & 4193 & 57.74 \\
& $\begin{array}{l}\text { Unexposed } \\
\text { Chemical hazards }\end{array}$ & 4733 & 51.90 \\
& Exposed & 5151 & \\
Total & $\begin{array}{l}\text { Unexposed } \\
\text { Exposed }\end{array}$ & 992 & 90.00 \\
\hline
\end{tabular}

respondents $(54.5 \%)$ were of junior professional ranks, $60.7 \%$ were undergraduates and $70 \%$ were married.

Of the five types of occupational exposure, the one with the highest exposure rate was psychosocial and organisational factors $(85.93 \%)$, followed by accidental $(70.78 \%)$, biological $(63.96 \%)$, physical $(57.74 \%)$ and chemical hazards $(51.90 \%)$. The overall occupational exposure rate was $90.00 \%$ for respondents, as shown in table 2 and figure 2.

Each dimension of occupational exposure includes four to nine items, and the total score of all items in a dimension is considered the score for the type of occupational exposure. For accidental hazards, a score of 9 is considered unexposed and a score of $\geq 10$ is considered exposed. For physical hazards, a score of 4 is unexposed and a score of $\geq 5$ is exposed. For chemical hazards, a score of 4 is unexposed and a score of $\geq 5$ is exposed. For biological hazards, a score of 4 is unexposed and a score of $\geq 5$ is exposed. For psychosocial and organisational factors, a score of 7 is unexposed and a score of $\geq 8$ is exposed.

The occupational exposure rate of the different types of respondents is shown in table 3 . The overall occupational

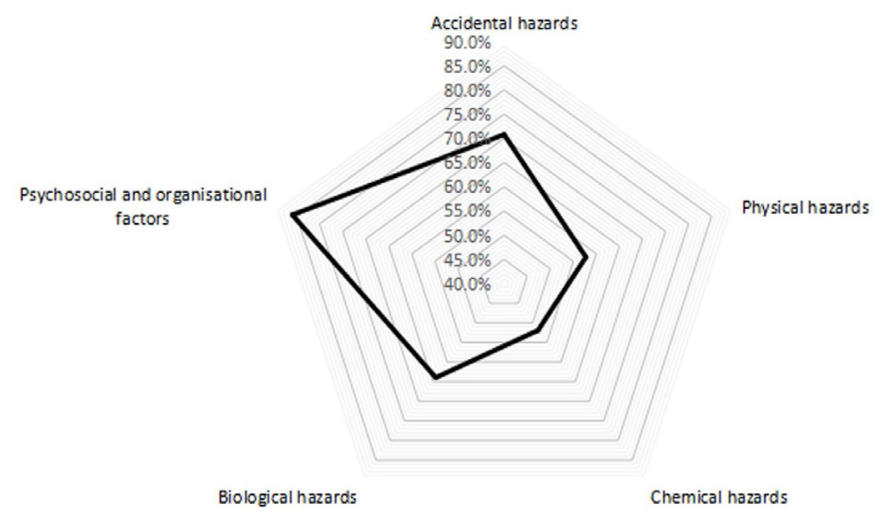

Figure 2 Incidence rate of the different types of occupational exposure. 
Table 3 Incidence of occupational exposure among different HCWs within the last 12 months

\begin{tabular}{llrl}
\hline $\begin{array}{l}\text { Categories of } \\
\text { HCWs }\end{array}$ & Exposure status & $\mathbf{n}$ & $\begin{array}{l}\text { Exposure } \\
\text { rate (\%) }\end{array}$ \\
\hline Physician & Unexposed (28) & 162 & \\
& Exposed $(\geq 29)$ & 2391 & 93.70 \\
Nurse & Unexposed (28) & 632 & \\
& Exposed $(\geq 29)$ & 5240 & 89.20 \\
Medical technician & Unexposed (28) & 136 & \\
& Exposed $(\geq 29)$ & 1013 & 88.20 \\
Pharmacist & Unexposed (28) & 32 & \\
& Exposed $(\geq 29)$ & 180 & 84.90 \\
Administrative & Unexposed (28) & 30 & \\
worker & Exposed $(\geq 29)$ & 108 & 78.30 \\
\hline
\end{tabular}

HCWs, healthcare workers.

exposure rate was $89.2 \%$ for nurses, $88.2 \%$ for medical technicians, $84.9 \%$ for pharmacists, $93.70 \%$ for physicians and $78.3 \%$ for administrative workers. It can be seen that physicians and nurses have a higher incidence of occupational exposure than other healthcare providers. The occupational exposure rates for different respondents are shown in figure 3 .

The means, SDs and Pearson's correlation coefficients of the study variables are shown in table 4 . These were calculated using a continuous score summing the subscores of each of the five types of occupational exposure. All variables significantly correlated with each other. Occupational exposure negatively correlated with work environment satisfaction $(\mathrm{r}=-0.464, \mathrm{p}<0.001)$ and job satisfaction $(\mathrm{r}=-0.380, \mathrm{p}<0.001)$. Occupational exposure positively correlated with stress symptoms $(\mathrm{r}=0.398$, $\mathrm{p}<0.001$ ).

The results of the mediation and moderation analyses are summarised in table 5. First, in this analysis, discipline types, type of department, service years, professional ranks and titles, level of education, gender, and marital status were treated as control variables in the regression

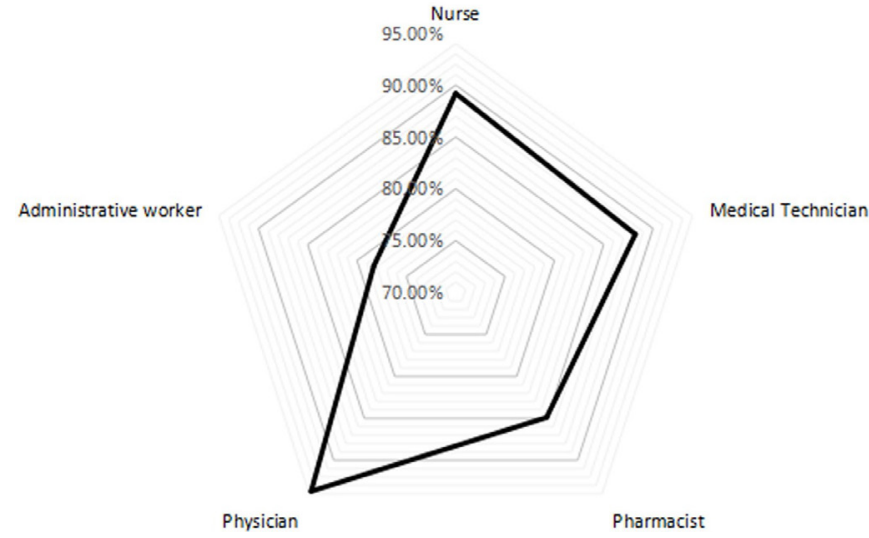

Figure 3 Occupational exposure rate of the different types of healthcare workers. equations. A model was constructed with work environment satisfaction (M) as a mediator and stress symptoms $(\mathrm{W})$ as a moderator. In this model, occupational exposure was set as the predictor (X) and job satisfaction as the outcome $(\mathrm{Y})$. We used 5000 bootstrap samples and determined the mediating effect using $95 \%$ CIs. The results showed that the conditional direct effect of $\mathrm{X}$ on $\mathrm{Y}$ was not significant $(\mathrm{p}=0.930)$ at the values of mediator $(\mathrm{M})$, and the indirect effect of $\mathrm{X}$ on $\mathrm{Y}$ was significant (lower limit $\mathrm{CI}=-0.269$, upper limit $\mathrm{CI}=-0.235$ ); therefore, work environment satisfaction played a mediating role in the relationship between occupational exposure (X) and job satisfaction $(\mathrm{Y})$. Hypothesis 1 was thus supported. Second, the interaction between occupational exposure and stress symptoms $\left(\mathrm{X}^{*} \mathrm{~W}\right)$ was significant $(\mathrm{p}<0.001)$. Therefore, stress symptoms moderated the relationship between occupational exposure and job satisfaction, and hypothesis 2 was thus supported.

In order to better display the moderation effect, we followed Aiken and West's procedures ${ }^{41}$ and the conditional indirect effects were examined at $1 \mathrm{SD}$ above the mean, at the mean, and at $1 \mathrm{SD}$ below the mean of stress symptoms as the moderator variable of interest. This analysis was done to determine if the slopes of the regression equations for high and low values of the interaction differed from each other. In figure 4, occupational exposure had a weaker effect on job satisfaction for those who reported low stress symptoms, whereas it had a stronger effect on job satisfaction for those who reported high stress symptoms. Finally, simple slope tests were conducted to further validate the moderation effects. The modified model and standardised path coefficients of the hypothetical model are shown in figure 5 .

\section{DISCUSSION}

\section{Occupational exposure status}

In the existing literature, most studies on occupational exposure focused on individual departments (such as nursing unit or work setting) and single types of exposure (blood exposure to needle injuries) ${ }^{42}{ }^{43}$ but overall concern for HCWs and comparative analysis of each type of occupational exposure are lacking. Previous studies have focused on the occupational injuries of nurses in different departments, ${ }^{44}$ but there are few studies investigating HCWs across different roles. In our analysis, we investigated the incidence of different occupational exposures experienced by various HCWs in the previous 12 months.

According to our large-sample survey, $85.93 \%$ of HCWs experienced psychosocial organisational hazards. Compared with accidental, physical, chemical and biological injuries, psychosocial organisational hazards (such as interpersonal conflict, work pressure and work role conflict) had a higher frequency of causing occupational damage to HCWs, with physicians and nurses reporting the highest incidence rates. This may be because HCWs commonly experience high work fatigue and 
Table 4 Mean (M), SD and correlation of variables

\begin{tabular}{|c|c|c|c|c|c|c|}
\hline Variables & $\mathbf{M}$ & SD & 1 & 2 & 3 & 4 \\
\hline 1. Occupational exposure & 1.76 & 0.61 & 1 & & & \\
\hline 2. Work environment satisfaction & 2.53 & 0.91 & $-0.464^{\star \star}$ & 1 & & \\
\hline 4. Job satisfaction & 3.27 & 0.83 & $-0.380^{\star \star}$ & $0.551^{\star \star}$ & $-0.426^{\star \star}$ & 1 \\
\hline
\end{tabular}

${ }^{* *} p<0.01$; Correlation is significant at the 0.01 level (2-tailed) M, Mean; SD, Standard deviation.

occupational, mental and physical stress. At the front lines of care delivery, HCWs are directly exposed to anxious patients and their families. Patients' desire to recover their health and medical uncertainty can easily lead to contradictions and conflicts, and patients' doubts and accusations can be experienced as an attack on HCWs. In addition, doctors and nurses have relatively more access to medical devices and pharmacists, which also increases their chances of experiencing occupational exposure.

Given HCWs' risk of occupational exposure reported here, Chinese hospital managers should undertake more measures to address the hidden physical and psychosocial injuries to HCWs by referring to the Occupational Safety and Health Administration established in the USA, which promotes the occupational health of HCWs through education, research, public policy and practice. ${ }^{45}$ First, according to the characteristics of Chinese hospitals, managers should formulate corresponding policies and measures to protect HCWs and reduce the frequency and intensity of occupational exposure (eg, establishing standardised preventive measures based on hospital characteristics, setting up a scientific scheduling system and managing medical waste strictly). Second, hospital managers should encourage HCWs to actively propose suggestions (eg, regular occupational safety training and contingency plans after occupational exposure), put effective suggestions into practice, and actively protect themselves while ensuring care quality and patient safety. Third, hospital administrators should advocate for the establishment of a more complete system of remedial measures for substantive injuries after occupational exposure (needlestick injuries, infections, physical violence in hospital places and so on) to minimise the harm of occupational exposure among HCWs. According to the results of this study, the problem with regard to occupational exposure among HCWs in China is serious. Therefore, it is suggested that occupational safety protection education be included in the medical education curriculum. ${ }^{46}$ In particular, the management department of medical institutions should actively set up medical occupational safety courses at all levels of education; improve the discipline system; participate in quality improvement plans; and make continuous efforts to improve doctors' knowledge, support patients' safety and promote HCWs' well-being, ensuring early training of medical staff on occupational safety awareness and related skills. In addition, occupational safety protection education should keep up with current developments, regularly organise centralised occupational safety training, constantly update HCWs' occupational safety knowledge and promote continuing education. Although risks in the health field cannot always be avoided, they can be adjusted and controlled through appropriate means to improve occupational safety management.

\section{Mediating role of work environment satisfaction}

Work environment satisfaction played a mediating role in the relationship between occupational exposure and job satisfaction according to the results of this study. Based on the existing risks of healthcare delivery, HCWs' vulnerabilities to occupational exposure were predictable. ${ }^{47}$ HCWs' job satisfaction will gradually worsen after prolonged exposure. ${ }^{48}$ According to the results of this study, there is a negative association between occupational exposure and HCWs' job satisfaction. As HCWs engage in occupational behaviour in the work environment, the risk of occupational exposure increases if they lack awareness and protection, ${ }^{49}$ increasing the possibility of occupational damage, which will inevitably increase their psychological pressure and work stress. ${ }^{50}$ However, the policy of most hospitals is inclined towards the provision of medical services, advocating "patient-centered care', while HCWs do not receive enough consideration or care after experiencing occupational exposure. What is even worse is that hospital occupational health regulations and technical standards are relatively lacking. For example, health damage to HCWs caused by occupational exposure to biological hazards has not been included in the scope of national occupational disease management. ${ }^{8}$

In recent years, medical institutions have begun to attach importance to process transformation, with the aim of improving patient experience and ultimately patient satisfaction. ${ }^{51}$ However, the work environment of HCWs should also be considered, as they are the main force providing medical services. Hospital managers need to increase their efforts to improve HCWs' work environment, for example by controlling the number of patients, strictly classifying medical waste and standardising medical tools (eg, injections and scalpels) for sample collection. As shown in this study, HCWs' satisfaction with their work environment plays a vital role in their job satisfaction. In other words, the influence of occupational exposure on HCWs' job satisfaction is mediated by their satisfaction with the work environment. The 


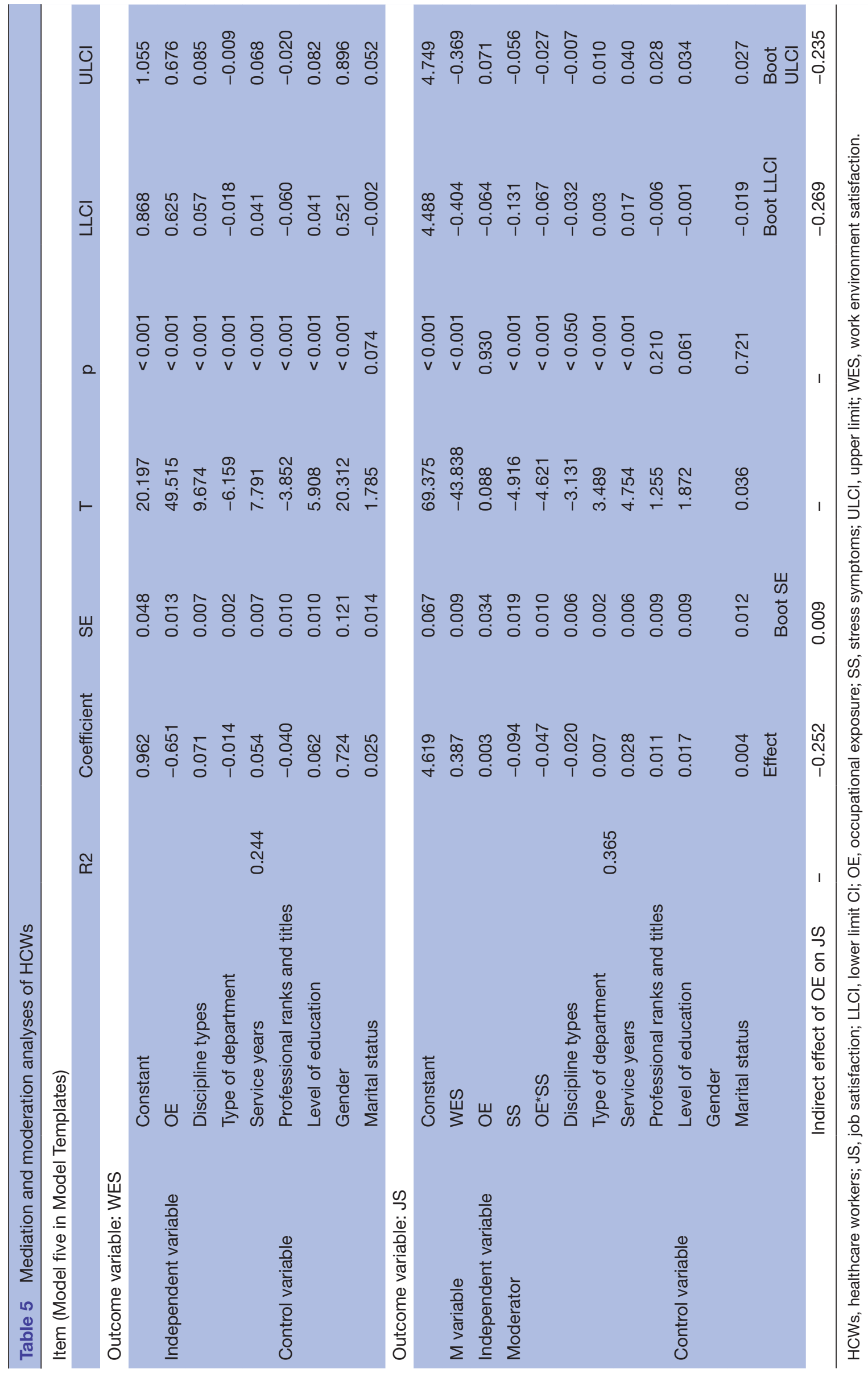




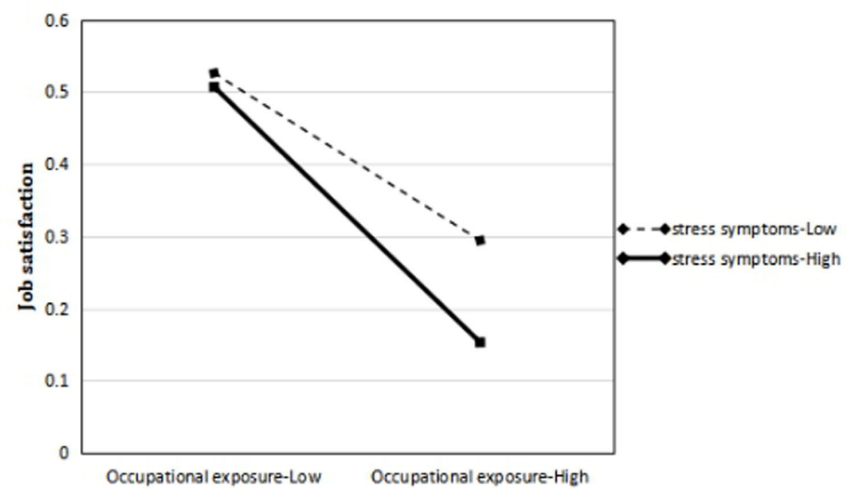

Figure 4 Effect of moderation.

role of the work environment has also been confirmed by previous studies. ${ }^{52} 53$ This clear mechanism provides a new reform idea for management of occupational safety and human resources in medical institutions. Building a safe diagnostic and therapeutic environment for both the HCWs and the patients is necessary to promote harmonious interaction. For example, at the organisational level, hospital managers should reasonably organise working hours, appropriately increase the authorised strength of HCWs and create an environment conducive to HCWs' growth. At the individual level, cultivating a positive and optimistic spirit, developing effective interpersonal communication skills, and improving social support system can help improve HCWs' work environment satisfaction.

\section{Moderating effect of stress symptoms}

From the point of view of HCWs, this large-sample study confirmed that the negative impact of occupational exposure on job satisfaction was greater for those with high stress symptoms. Contrarily, for those with low anxiety, occupational exposure had a weaker negative impact on job satisfaction. This has become a breakthrough point for managers of medical institutions to implement occupational safety management; they need to consider ways to buffer the negative impact of occupational exposure on HCWs' job satisfaction. Individual stress is closely related to work environment, but it is also affected by the degree of work adaptation. ${ }^{54}$ Stress can be caused by many different factors. HCWs with high stress symptoms prior to being exposed to occupational hazards are perhaps more at risk

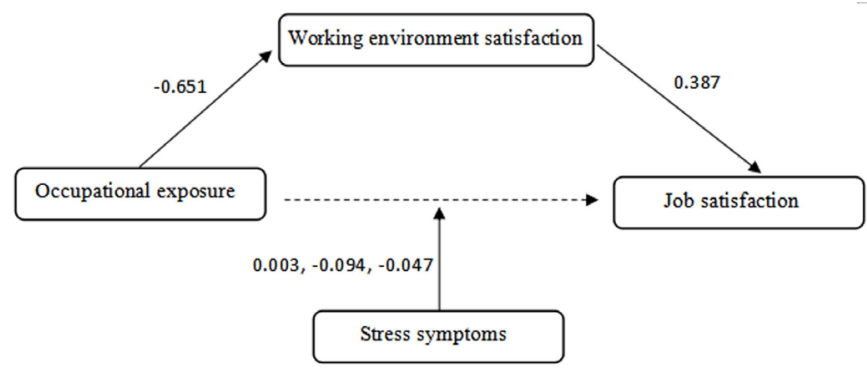

Figure 5 Modified model and standardised path coefficients. of the negative consequences of that exposure, including lower job satisfaction. At the same time, the mechanism of the impact of occupational exposure on HCWs' job satisfaction revealed in this study provides evidence for the implementation of stress management programmes in hospitals. Such programmes can not only increase the professional embeddedness of HCWs and hospitals but also enhance HCWs' sense of professional mission, ultimately reducing turnover rate and improving the quality of medical human resources management. Hospital managers should increase effective channels for HCWs to relieve stress in postoccupational intervention. Specifically, hospital administrators need to support HCWs in terms of occupational exposure by conducting timely examinations and treatment, actively building and reinforcing the post-treatment process of occupational exposure, and providing psychological counselling for those injured by serious occupational exposure. Re-education regarding occupational safety protection should be carried out to enhance occupational safety awareness and reduce workers' stress symptoms to minimise the negative impact of occupational exposure.

\section{CONCLUSION}

Based on large-sample data, this study investigated the incidence of five types of occupational exposure among HCWs in China, innovatively including physical and psychosocial injuries caused by the hospital environment. In addition, at the organisational level, this study confirmed the mediating role of HCWs' work environment satisfaction in the influence of occupational exposure on job satisfaction. At the individual level, HCWs' anxiety level negatively regulated the impact of occupational exposure on job satisfaction. This provides empirical evidence for healthcare managers in China to formulate occupational health protection policies. The continuous development of healthcare delivery will be accompanied by new occupational hazards; consequently, minimising occupational exposure will be an ongoing and evolving necessity. We recommend the inclusion of occupational safety education in teaching materials and curricula at nursing and medical colleges, strengthening management and implementing effective protective measures, so that HCWs can actively participate in ensuring occupational safety.

\section{Limitations}

Although the present study has significant findings, it also has several limitations. First, a convenient sample was used, which creates potential for sampling bias. The questionnaire distribution method used in this study may lead to potential but incalculable sample size bias. Second, the study's crosssectional nature prevented the establishment of a causal relationship between variables. Therefore, one important suggestion is that longitudinal studies be conducted in the future. Third, these data are based on an online survey of self-reported occupational exposure and psychological factors of Chinese HCWs over 12 months, which may lead to errors in data due to memory bias. Fourth, the measurement of work environment satisfaction, stress symptoms 
and job satisfaction using one item weakens the assessment and reduces the validity of the tools used. Moreover, considering the sampling characteristics, the results of the study are not generalisable to all HCWs.

\section{Author affiliations}

${ }^{1}$ School of Health Management, Harbin Medical University, Harbin, China

${ }^{2}$ Department of Nutrition and Food Hygiene, School of Public Health, Qiqihar Medical College, Qiqihar, China

${ }^{3}$ Office of the Outpatient Department of the Fourth Affiliated Hospital, Harbin Medical University, Harbin, China

${ }^{4}$ Performance Office, Jinan Central Hospital, Jinan, China

${ }^{5}$ Office of Coordination of Doctor-Patient Relations, Beijing Hospital of Traditional Chinese Medicine Affiliated to Capital Medical University, Beijing, China

${ }^{6}$ Doctor-Patient Office, Beijing Friendship Hospital Affiliated to Capital Medical University, Beijing, China

${ }^{7}$ Medical Insurance Office, The First Affiliated Hospital of Harbin Medical University, Harbin, China

${ }^{8}$ Department of Marketing, College of Humanities and Social Sciences, Harbin Medical University, Harbin, China

Acknowledgements We acknowledge the support of the National Natural Science Foundation of China: Trajectory simulation and multistage dynamic prevention and control model of medical disputes evolving into medical disturbances.

Contributors Conceived and designed the experiments: LF, YS, HX. Performed the experiments: YM, LW, ML. Analysed the data: TG, LS, YW. Contributed reagents/ materials/analysis tools: MC, CW, XY. Wrote the paper: YS, GY.

Funding This research was funded by the Innovation Project for Postgraduates of Harbin Medical University and the National Natural Science Foundation of China (grant numbers 71473063 and 71874043 ).

Competing interests None declared.

Patient consent for publication Not required.

Ethics approval The study was conducted in compliance with the ethical guidelines of the Ethics Committee of the College of Public Health, Harbin Medical University (HMUIRB20180305), and approved by the Ethics Committee of the Harbin Medical University. It was not possible to seek written informed consent from participants due to the study's confidential survey approach. However, on the front page of the questionnaire, we clearly indicated that the survey was confidential and voluntary. Hence, the completion and successful submission of the questionnaire were considered as consent of the HCW to participate in our investigation.

Provenance and peer review Not commissioned; externally peer reviewed.

Data availability statement № additional data are available.

Open access This is an open access article distributed in accordance with the Creative Commons Attribution Non Commercial (CC BY-NC 4.0) license, which permits others to distribute, remix, adapt, build upon this work non-commercially, and license their derivative works on different terms, provided the original work is properly cited, appropriate credit is given, any changes made indicated, and the use is non-commercial. See: http://creativecommons.org/licenses/by-nc/4.0/.

ORCID iD

Yu Shi http://orcid.org/0000-0002-9349-5529

\section{REFERENCES}

1 Goodnough CP. Risks to health care workers in developing countries. N Engl J Med 2001;345:1916.

2 DiBenedetto DV. Occupational hazards of the health care industry: protecting health care workers. Aaohn J 1995;43:131.

3 O'Neill TM, Abbott AV, Radecki SE. Risk of needlesticks and occupational exposures among residents and medical students. Arch Intern Med 1992;152:1451-6.

4 Maguire BJ, O'Meara PF, Brightwell RF, et al. Occupational injury risk among Australian paramedics: an analysis of national data. Med $\mathrm{J}$ Aust 2014;200:477-80.

5 Roberts $\mathrm{MH}$, Sim MR, Black O, et al. Occupational injury risk among ambulance officers and paramedics compared with other healthcare workers in Victoria, Australia: analysis of workers' compensation claims from 2003 to 2012. Occup Environ Med 2015;72:489-95.

6 Reichard AA, Marsh SM, Moore PH. Fatal and nonfatal injuries among emergency medical technicians and paramedics. Prehosp Emerg Care 2011;15:511-7.

7 Kirch W. Occupational exposure. encyclopedia of public health. Dordrecht: Springer Netherlands, 2008: 1024-5.

8 Nurse, occupational health: International Hazard Datasheets on Occupation[EB/OL]. Available: https://www.ilo.org/safework/cis/ WCMS_192435/lang--en/index.htm

9 Nygren O, Gustavsson B, Ström L, et al. Exposure to anti-cancer drugs during preparation and administration. Investigations of an open and a closed system 2002;4:739-42.

10 Tsigonia A, Lagoudi A, Chandrinou S, et al. Indoor air in beauty salons and occupational health exposure of cosmetologists to chemical substances. Int J Environ Res Public Health 2010;7:314-24.10.3390/ijerph7010314

11 Ljiljana M, Miloš $B$, Nataša M, et al. Occupational exposures to blood and body fluids among health care workers at university hospitals 2013;141:789.

12 Markovicdenic L, Maksimovic N, Marusic V, et al. Occupational exposure to blood and body fluids among health-care workers in Serbia 2015;24:36-41.

13 Cooke CE, Stephens JM. Clinical, economic, and humanistic burden of needlestick injuries in healthcare workers 2017;10:225-35.

14 Matsubara C, Sakisaka K, Sychareun V, et al. Prevalence and risk factors of needle stick and sharp injury among tertiary hospital workers, Vientiane, Lao PDR. J Occup Health 2017;59:581-5.

15 Xie Z, Wang A, Chen B. Nurse burnout and its association with occupational stress in a cross-sectional study in Shanghai. J Adv Nurs 2011;67:1537-46.

16 Crilly J, Chaboyer W, Creedy D, et al. Violence towards emergency department nurses by patients. Accid Emerg Nurs 2004;12:67-73.

17 The Lancet. Violence against doctors: why China? why now? what next? Lancet 2014;383:1013-13.

18 Zhang $\mathrm{M}$, Wang $\mathrm{H}$, Miao J, et al. Occupational exposure to blood and body fluids among health care workers in a general Hospital, China 2010;52:89-98.

19 Neuberger J, Vergani D, Mieli-Vergani G, et al. Hepatic damage after exposure to halothane in medical personnel. Br J Anaesth 1981;53:1173-7.

20 Seabra SNJ, Carvalho MAL, REAJBJoID C. The first case of AIDS due to occupational exposure in Brazil 2002;6:140-1.

21 Bhebhe LT, Van Rooyen C, Steinberg WJ. Attitudes, knowledge and practices of healthcare workers regarding occupational exposure of pulmonary tuberculosis. Afr J Prim Health Care Fam Med 2014;6:E1-6.

$22 \mathrm{He}$ AJ, Alex Jingwei $\mathrm{H}$. The doctor-patient relationship, defensive medicine and Overprescription in Chinese public hospitals: evidence from a cross-sectional survey in Shenzhen City. Soc Sci Med 2014;123:64-71.

23 The Lancet. Violence against doctors in China. BMJ 2014;384:e5730.

24 Shan HP, Yang XH, Zhan XL, et al. Overwork is a silent killer of Chinese doctors: a review of Karoshi in China 2013-2015. Public Health 2017;147:98-100.

25 Sun T, Gao L, Li F, et al. Workplace violence, psychological stress, sleep quality and subjective health in Chinese doctors: a large crosssectional study. BMJ Open 2017;7:e017182.

26 Judge TA, Thoresen CJ, Bono JE, et al. The job satisfaction-job performance relationship: a qualitative and quantitative review. Psychol Bull 2001;127:376-407.

27 Spector PE. Job satisfaction: application, assessment, causes, and consequences 1997.

28 Wu D, Wang Y, Lam KF, et al. Health system reforms, violence against doctors and job satisfaction in the medical profession: a cross-sectional survey in Zhejiang Province, eastern China. BMJ Open 2014;4:e006431

29 Porter LW, Steers RM, Mowday RT, et al. Organizational commitment, job satisfaction, and turnover among psychiatric technicians. Journal of Applied Psychology 1974;59:603-9.

30 Yang $\mathrm{T}$, Zhang $\mathrm{H}$, Shen $\mathrm{F}$, et al. Appeal from Chinese doctors to end violence. Lancet 2013;382:1703-4.

31 Duan G, Quu L, Yu W, et al. Outpatient service quality and doctorpatient relationship: a study in Chinese public hospital. IJSEM 2014;6:97-111.

32 Piasecka L. Teaching matters: enjoyment and job satisfaction 2016

33 Asnaani A, Reddy MK, Shea MT. The impact of PTSD symptoms on physical and mental health functioning in returning veterans. $J$ Anxiety Disord 2014;28:310-7. 
34 Aust B, Rugulies R, Skakon J, et al. Psychosocial work environment of hospital workers: validation of a comprehensive assessment scale. Int J Nurs Stud 2007;44:814-25.

35 McGillis Hall L, Doran D. Nurses' perceptions of hospital work environments. J Nurs Manag 2007;15:264-73.

36 Li H, Song Y, Wang X. Development and evaluation of nursing occupational risk assessment tool. Chinese Journal of Nursing 2008;43:651-4.

37 Niu J. Investigation on nursing occupational risk in six general hospitals in Shanxi Province. Shanxi Medical University, 2010.

38 Elo A-L, Leppänen A, Jahkola A. Validity of a single-item measure of stress symptoms. Scand J Work Environ Health 2003;29:444-51.

39 Dolbier CL, Webster JA, McCalister KT, et al. Reliability and validity of a single-item measure of job satisfaction. Am J Health Promot 2005;19:194-8.

40 Hayes A. Introduction to mediation, moderation, and conditional process analysis. J Edu Measur 2013;51:335-7.

41 Aiken LS WS, Reno RR. Multiple Regression: testing and interpreting interactions. Sage, 1991.

42 Shariati B, Shahidzadeh-Mahani A, Oveysi T, et al. Accidental exposure to blood in medical interns of Tehran University of medical sciences. J Occup Health 2007;49:317-21.

43 van Wijk PTL, Pelk-Jongen M, Wijkmans $C$, et al. Variation in interpretation and counselling of blood exposure incidents by different medical practitioners. Am J Infect Control 2008;36:123-8.

44 Kosgeroglu N, Ayranci U, Vardareli E, et al. Occupational exposure to hepatitis infection among Turkish nurses: frequency of needle exposure, sharps injuries and vaccination. Epidemiol Infect 2004:132:27-33.

45 Watson D. Occupational safety and health administration 2011.

46 Yao W-X, Wu Y-L, Yang B, et al. Occupational safety training and education for needlestick injuries among nursing students in China: intervention study. Nurse Educ Today 2013;33:834-7.

47 Donnelly E, Siebert D, Elizabeth D. Occupational risk factors in the emergency medical services. Prehosp Disaster Med 2009;24:422-9.

48 Kuan-Yu C C-MY, Che-Hui L, et al. Burnout, job satisfaction, and medical malpractice among physicians. International Journal of MedicineSciences 2013;10:1471-8.

49 Swetharani VKV, Hamide A, et al. Awareness of blood-borne infections and burden of occupational exposures to blood and body fluids among health care personnel in a tertiary care teaching hospital 2016;20:138-43.

50 Armstrong K, Gorden R, Santorella G. Occupational exposure of health care workers (HCWs) to human immunodeficiency virus (HIV). Soc Work Health Care 1995;21:61-80.

51 Cronholm PF, Shea JA, Werner RM, et al. The patient centered medical home: mental models and practice culture driving the transformation process. J Gen Intern Med 2013;28:1195-201.

52 Zhang L-feng, You L-ming, Liu K, et al. The association of Chinese hospital work environment with nurse burnout, job satisfaction, and intention to leave. Nurs Outlook 2014;62:128-37.

53 Røssberg JI, $\varnothing \mathrm{E}$, Friis S, et al. Work environment and job satisfaction 2004;39:576-80.

54 Folkman S. Stress: appraisal and coping, 2013. 